\title{
ANALISA DAN PERANCANGAN E-COMMERCE PADA DISTRO DAN EIGER CENTRE ULAK KARANG KOTA PADANG BERBASIS WEB DAN DATABASE MYSQL
}

\author{
Ronaldo Syahputra \\ Universitas Putra Indonesia YPTK Padang \\ syahputraronaldo07@gmail.com
}

\begin{abstract}
Abstrak
Tujuan dari perancangan sistem informasi ini adalah membantu Distro dan Eigar Center Ulak Karang Kota Padang dalam proses penjualan dan pemasaran produk secara cepat dan mudah. Metode analisis adalah menganalisa sistem lama dan merancang sistem yang baru. Rancangan sistem menggunakan bahasa pemrograman PHP dan didukung dengan database MySQL sehingga pemasaran produk menjadi berbasis e-commerce (online). Hasil implementasi sistem dengan bahasa pemrograman PHP ini adalah penjualan dan pemasaran produk mudah dilaksanakan karena program aplikasi sistem baru ini terdapat database MySQL sebagai media penyimpanan data yang pasti, akurat dan terjamin keasliannya, serta media internet yang memberi kemudahan dan informasi produk yang dibutuhkan dapat dilihat setiap saat dengan mudah dan kapanpun jika dibutuhkan, informasi yang dihasilkan oleh sistem ini pun lebih jelas dan terinci. Akhirnya penulis menyarankan agar dilakukan penggantian sistem lama dengan sistem baru dan dalam penerapan sistem yang baru ini sebaiknya didukung oleh perangkat yang memadai baik dari segi sumber daya manusia maupun dari segi peralatan sehingga sistem yang baru ini dapat dimanfaatkan secara maksimal.
\end{abstract}

Kata kunci: e-commerce, PHP, mysql

\section{Pendahuluan}

Persaingan bisnis pada setiap perusahaan semakin ketat dirasakan pada era globalisasi sekarang ini. Hal itu dapat dilihat dari beberapa perusahaan yang kini teknologi informasi dan komunikasinya semakin meningkat. Penyebaran informasi melalui internet menjadi salah satu pilihan dari beberapa perusahaan untuk menigkatkan persaingan mereka di dalam bisnis.

Teknologi informasi melalui internet sangat berkembang pesat saat ini. Manfaat yang besar dalam penggunaan internet semakin banyak digunakan oleh perusahaan dalam masyarakat untuk menunjang usaha kerja mereka. Tidak hanya bermanfaat dalam informasi saja, tetapi internet juga dapat di jadikan media promosi dan penjualan untuk memasarkan produk perusahaan secara efektif dan efisien. Salah satu contohnya yaitu menggunakan sistem penjualan barang kebutuhan manusia secara online. Sistem penjualan tersebut merupakan suatu bentuk kegiatan pemasaran produk serta pemesanan produk oleh konsumen dengan menggunakan suatu aplikasi penjualan yang didukung jaringan internet untuk mencapai jangkauan wilayah secara global.

Salah satu perusahaan yang akan memanfaatkan teknologi informasi yang berbasis web adalah Distro dan Eiger Centre yang merupakan sebuah perusahaan dagang yang menjual dan memasarkan produk pakaian jadi, tas, sendal, sepatu serta aksesoris pria dan wanita produksi dalam negri secara grosiran atau eceran dengan bermacam brand yang sudah dikenal masyarakat. Sampai saat ini promosi dan penjualan produk dilakukan secara manual di berbagai outlet. Belum ada sistem informasi yang dirancang untuk memberikan kemudahan dalam proses penjualan dan pemasaran produk kepada konsumen. Oleh karena 
itu dibutuhkan suatu pendekatan kepada konsumen secara efektif dan efisien agar dapat meningkatkan penjualan serta dapat bersaing dalam era globalisasi seperti saat ini.

Diharapkan dengan diterapkannya sistem penjualan, dan pemasaran secara online ini akan dapat membantu Distro dan Eiger Centre Ulak Karang dalam menjalankan promosi untuk memasarkan produk-produk perusahaan, serta mempermudah pimpinan dalam hal pengambilan keputusan.

Makalah harus berisi Latar Belakang, pernyataan, Rasional.

\section{Tinjauan Literatur}

\subsection{Pengertian E-Commerce}

"Suatu proses berbisnis dengan memakai teknologi elektronik yang menghubungkan antara perusahaan, konsumen dan masyarakat dalam bentuk transaksi elektronik dan pertukaran atau penjualan barang, servis dan informasi secara elektronik". (Munir Fuady, 2005)

\subsection{Jenis - Jenis Transaksi E-Commerce}

Menurut Onno W. Purbo dan Aang Arif Wahyudi (2001), kegiatan e-commerce mencakup banyak hal, untuk membedakannya e-commerce dibedakan menjadi 2 berdasarkan karakteristiknya:

a. Bussines to Bussines (B2B)

\section{Karakteristik:}

1. Trading partners yang sudah saling mengetahui dan antara mereka sudah terjalin hubungan yang berlangsung cukup lama.

2. Pertukaran data dilakukan secara berulang-ulang dan berkala dengan format data yang telah disepakati bersama.

3. Salah satu pelaku tidak harus menunggu rekan mereka lainnya untuk mengirimkan data.

4. Model yang umum digunakan adalah peer to peer dimana processing intelligence dapat didistribusikan di kedua pelaku bisnis.

b. Bussines to Consumer (B2C)

Karakteristik:

1. Terbuka untuk umum, dimana informasi disebarkan secara umum pula.

2. Servis yang digunakan juga bersifat umum, sehingga dapat digunakan oleh orang banyak

3. Servis yang digunakan berdasarkan permintaan.

4. Servis dilakukan sistem pendekatan client-server.

\subsection{Manfaat E-Commerce}

Menurut Onno W. Purbo (2007:6), manfaat dalam menggunakan ecommerce dalam suatu perusahaan sebagai system transaksi adalah:

1. Dapat meningkatkan pangsa pasar (market exsposure)

Transaksi on-line yamg membuat semua orang di seluruh dunia dapat memesan dan membeli produk yang dijual hanya dengan melalui media komputer dan tidak terbatas jarak dan waktu.

2. Menurunkan biaya operasional (operating cost) 
Transaksi e-commerce adalah transaksi yang sebagian besar operasionalnya diprogram di dalam komputer sehingga biaya-biaya seperti toko, beban gaji yang berlebihan dan lain-lain tidak perlu terjadi.

3. Melebarkan jangkauan

Transaksi on-line yang dapat diakses oleh semua orang di dunia tidak terbatas tempat dan waktu karena semua orang dapat mengaksesnya hanya dengan menggunakan media perantara komputer.

4. Meningkatkan customer loyalty

Ini disebabkan karena sistem e-commerce menyediakan informasi secara lengkap dan informasi tersebut dapat diakses setiap waktu . Selain itu dalam hal pembelian juga dapat dilakukan setiap waktu bahkan konsumen dapat memilih sendiri produk yang dia inginkan.

5. Meningkatkan supply management

Transaksi e-commerce menyebabkan pengefisienan biaya operasional pada perusahaan terutama pada jumlah karyawan dan jumlah stok barang yang tersedia sehingga untuk lebih menyempurnakan pengefisienan biaya tersebut maka sistem supply management yang baik harus ditingkatkan.

6. Memperpendek waktu produksi.

Pada suatu perusahaan yang terdiri dari berbagai divisi atau sebuah distributor dimana dalam pemesanan bahan baku atau produk yang akan dijual apabila kehabisan barang dapat memesannya setiap waktu karena on-line serta akan lebih cepat dan teratur karena semuanya secara langsung terprogram dalam komputer.

\section{Metodologi}

Metodologi yang digunakan dalam pembuatan tugas akhir ini yaitu :

1. Pengambilan data:

Studi pustaka untuk mencari informasi yang berhubungan dengan teori-teori yang berkaitan dengan penelitian ini. Studi kepustakaan dilakuakan dengan membaca, mempelajari dan menarik beberapa kesimpulan dari sumber yang dijadikan referensi, baik dalam bentuk buku, majalah dan jurnal yang berkaitan dengan sistem penjualan sepatu, sandal, tas secara online dalam website.

2. Laboratory Research (Penelitian Labor)

Dengan melakukan penelitian dan pengamatan langsung tehadap website yang sudah ada secara langsung, kemudian dilakukan perancangan sistem sesuai kebutuhan. Untuk itu dibutuhkan sebuah perangkat personal Komputer dengan peralatan Software dan Hardware sebag ai berikut :

a. Hardware

Yaitu : perangkat-perangkat keras yang penulis gunakan dalam melakukan pengolahan data seperti :
a. Processor Intel ${ }^{\circledR}$ Core $^{\mathrm{TM}} 2$ duo processor T5550
b. Monitor Acer 14 inch
c. Printer Canon IP 1880
d. d. Memori 512 Mbyte
e. Hardisk 160 Gbyte

b. Software

Yaitu perangkat-perangkat lunak yang penulis gunakan untuk membuat sistem Dan sekaligus dalam melakukan pengolahan data seperti :
a. Microsoft Windows XP
b. Microsoft Office 2007
c. Microsoft Visio 2003
d. Notepad++
e. MYSQL
f. Macromedia Dreamwever 8.0. 


\section{Hasil dan Diskusi}

Pada bab ini akan dibahas mengenai hasil implementasi sistem e-commerce yang telah dirancang. Beberapa gambar berikut akan menjelaskan bagaimana sistem ini berjalan;

\subsection{Tampilan Homepage}

Jendela Homepage ini merupakan interface utama yang menghubungkan user dengan aplikasi ini, yang terdiri dari Register, Login, Daftar Produk, dan Kantong Belanja. Tampilan homepage dapat dilihat pada gambar 4.1 berikut ini:

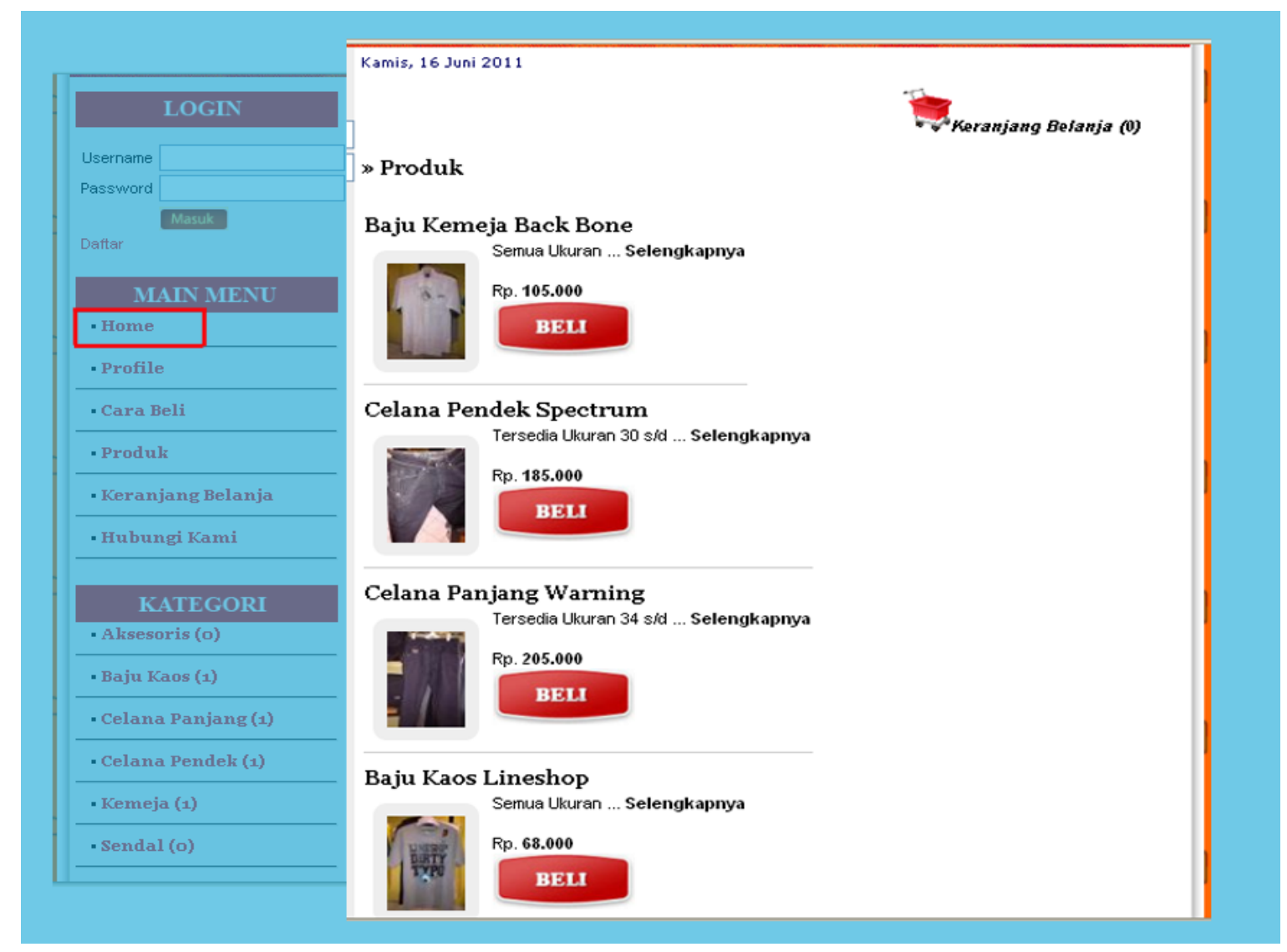

\section{Gambar 4.1 Tampilan Homepage}

\subsection{Tampilan Halaman Registrasi Member}

Halaman ini berfungsi untuk pelanggan mendaftarkan diri menjadi member di Distro dan Eiger Center, dengan memasukkan data-data pribadi. Dimana data yang telah dimasukkan tersebut akan tersimpan ke database dan selanjutnya akan dipergunakan untuk proses transaksi belanja. Tampilan halaman registrasi tersebut dapat dilihat pada gambar 4.2 berikut ini: 


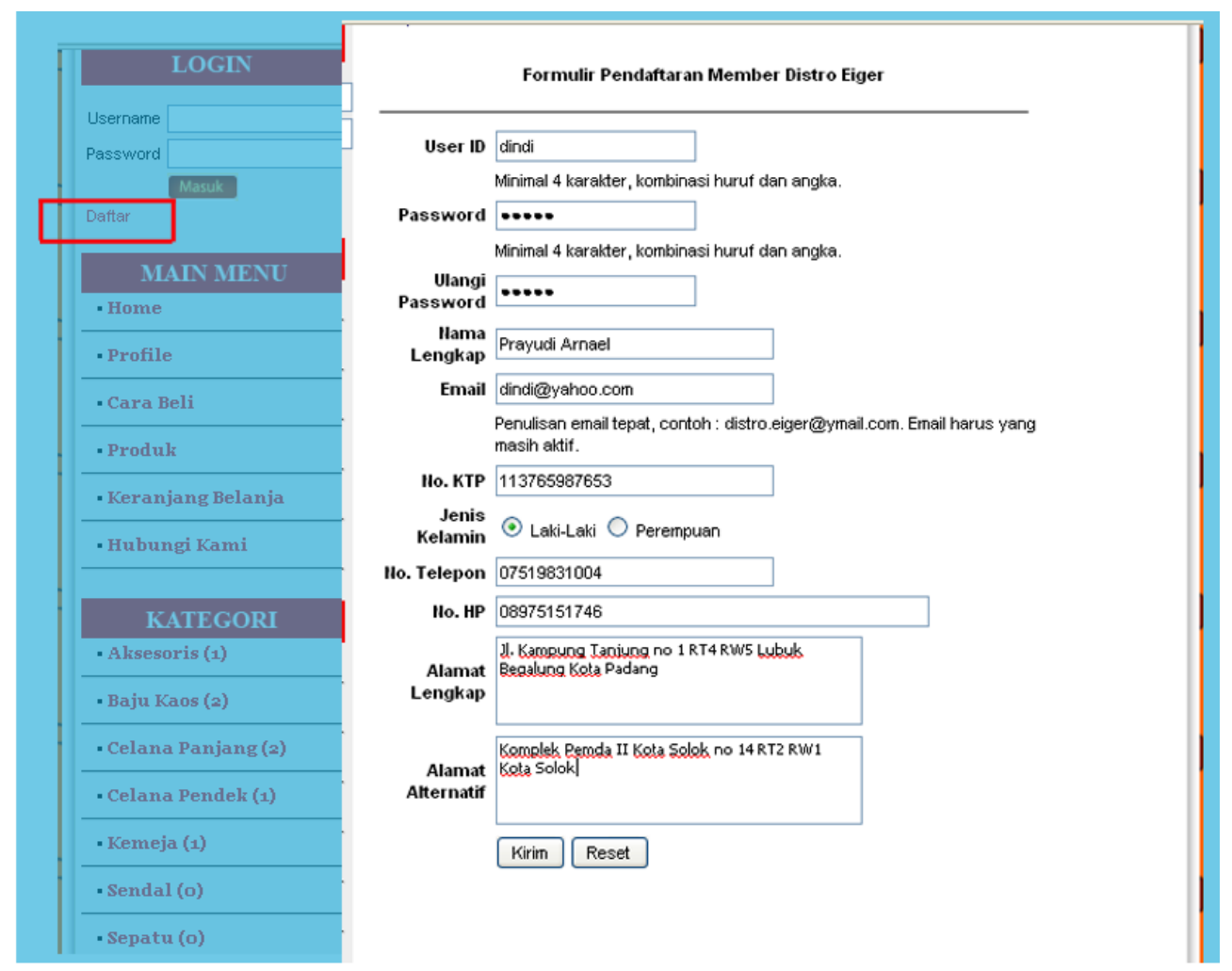

Gambar 4.3 Tampilan halaman Registrasi Pelanggan

\subsection{Tampilan Login Member}

Halaman ini berfungsi untuk login member dengan mengisi Email dan Password agar dapat melakukan transaksi pembelian produk. Tampilan login member tersebut dapat dilihat pada gambar 4.3 berikut ini:

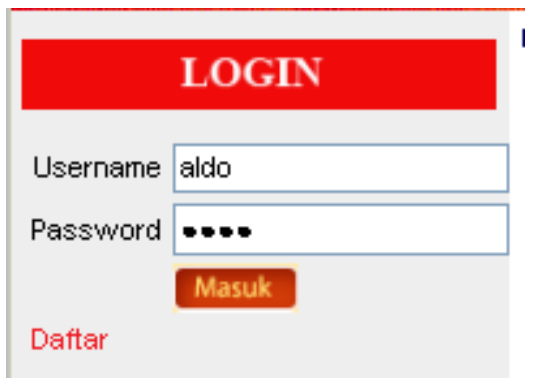

\section{Gambar 4.3 Tampilan Login Member}

\subsection{Diskusi Hasil}

Berdasarkan hasil dari implementasi sistem e-commerce ini maka dapat disimpulkan bahwa sistem yang dibangun ini dapat membantu pihak Distro dan Eiger Center dalam memasarkan produknya secara global. Dan sistem ini juga dapat membantu meningkatkan penjualan karena pelanggan bukan hanya dapat melakukan transaksi pembelian secara langsung tapi juga dapat bertransaksi secara online.

\section{Kesimpulan}

Berdasarkan hasil pengamatan dan analisa perancangan sistem yang telah dilakukan, maka dapat diambil beberapa kesimpulan yaitu: 
1. Dengan adanya aplikasi e-commerce (penjualan dan pemasaran secara online), informasi mengenai produk yang dijual di Distro dan Eiger Center ini dapat dipublikasikan ke pelanggan yang sering online.

2. Dengan adanya aplikasi e-commerce ini, maka akan lebih mudah dalam melakukan aktifitas penjualan secara global terhadap masyarakat .

3. Efisiensi waktu dalam pemahaman informasi .

4. User atau pelanggan dapat mempelajari dan terbiasa dengan sistem transaksi online .

5. Admin dapat melakukan pengawasan dan kontrol secara cepat untuk mengetahui informasi tentang perkembangan pemesanan produk dengan adanya penginputan data secara online.

6. Aplikasi e-commerce ini dapat dijadikan sebagai ajang kompetisi antara sesama pebisnis yang bergerak di bidang penjualan busana dalam memasarkan produk ke public dan lain sebagainya.

7. Aplikasi e-commerce ini akan selalu dikembangkan seiring dengan kemajuan teknologi.

\section{Referensi}

[1] H.M Jogiyanto, "Analisa Dan Desain Sistem Informasi: Pendekatan Terstruktur, Teori dan Praktik Aplikasi Bisnis", 2005.

[2] Abdul Kadir, "Mudah Mempelajari Database MySql", 2009.

[3] Rulianto Kurniawan, "Membangun situs dengan PHP untuk orang awam", 2008

[4] Rulianto Kurniawan, "Membangun situs dengan PHP untuk orang awam", $2^{\text {nd }}$ ed., 2008

[5] Onno W. Purbo and Aang Arif Wahyudi, "Mengenal E-Commerce", 2001 